\title{
Perceived Organizational Support Predicts Emotional Labor Among Nurses
}

\author{
Syeda Razia Bukhari ${ }^{1}$, Nargis Aftab Alam ${ }^{2}$, Azra Batool ${ }^{1}$, Yawar Hussain ${ }^{1}$, Sitara Asim ${ }^{1}$, Naveeda Khatttak ${ }^{1}$, \& \\ Shafia Tabassum ${ }^{1}$ \\ ${ }^{1}$ Department of Social Sciences, Shaheed Zulfikar Ali Bhutto Institute of Science and Technology H-8/4 \\ Islamabad \\ ${ }^{2}$ National Institute of Psychology, Quaid-e-Azam University, Islamabad \\ Correspondence: Syeda Razia Bukhari. E-mail: drsyedaraziabukhari@hotmail.com
}

Received: December 12, 2019

Accepted: December 23, 2019

Online Published: January 31, 2020

doi:10.5539/ass.v16n2p68

URL: https://doi.org/10.5539/ass.v16n2p68

\begin{abstract}
Background: Nursing is among the various occupations that require management of emotions according to the job demands. Emotional labor and lack of reward are the main sources of mental health outcomes among the nurses. It is very important that more researches, which contemplate the emotional labor importance and unfavorable mental health effects, be carried out.
\end{abstract}

Aim: This study was aimed to investigate the effect of perceived organizational Support on emotional labor among nurses.

Method: The present study was a correlational study, consist of 200 nurses both Male nurses $(\mathrm{N}=100)$ and Females nurses $(\mathrm{N}=100)$, from different hospitals and clinics. Age ranged from 20 to 51 years $(M=30.50 ; S . D=$ 4.40). Data of the study was collected through convenient sampling technique. Participants were assessed by Shorten Version of Survey of Perceived Organizational Support (Eisenberger et al, 1986) in order to measure perceived organizational support and Dutch Questionnaire on Emotional Labor (D-QEL) (Näring, Briët, \& Brouwers, 2007) in order to assess emotional labor.

Results: The results revealed that perceived organizational support significantly predicts emotional labor. By improving the perception of organizational support among nurses, the experience of emotional labor can be reduced.

Conclusion: The purpose of the present study was to develop a health-care model of emotional labor which could help the organizations to understand the role of perceived organizational support on the reactions to the strain of the emotional labor. The present study revealed that perceived organizational support is a significant predictor of emotional labor. Informal types of organizational support (e.g., a perception that the organization is concerned with one's personal life) are important for expatriate success, and should be incorporated into expatriate programs.

Keywords: perceived organizational support, emotional labor, nurses

\section{Introduction}

Researchers and psychologists have been interested in the management of emotions since initial Greek philosopher's era. But it becomes a formulized research topic in recent years meanwhile from 1950s (Leary, 1995). Emotions in the organization have growing interest from past several years among researchers. Researchers have argued that study on the emotions in organization can enhance our understanding of organizational behaviors (Fisher \& Ashkanasy, 2000). Nursing and emotional labor are one of the popular concepts within the emotional labor occupations (Bolton, 2001).

Morris and Feldman (1996), defined emotional labor as a regulation of emotions to display organizationally desired emotions that an individual express during interpersonal dealings. What type of emotions an employee should express in a particular condition or which emotions should not express are postulated through display rules, officially or offhandedly. Display rules are hypothesized as a shared, although, often hidden set of rules (Hochschild, Irwin, \& Ptashne, 1983). Display rules, basically, define the emotions that are expected from the 
workers (Ashforth \& Humphrey, 1993).

These display rules can be achieved through different strategies which include surface acting, deep acting, and expression of genuine emotions (Ashforth \& Humphrey, 1993). Surface acting is a management of behavior instead of internal change. i.e., voice tone or body language (Brotheridge \& Grandey, 2002). In surface acting individual just express desired emotions externally or behaviorally, regardless of whether an individual feel the similar emotion internally or not (Brotheridge \& Grandey, 2002). Deep acting has been defined as management of internal feelings to meet the desired display emotions (Brotheridge, 2006). In deep acting individual internalize the organizationally displayed emotions (Brotheridge \& Grandey, 2002). Genuine emotions refer to the actually felt emotions. Ashforth and Humphrey (1993) argued that sometimes employee doesn't need to manage the emotions to meet the organizationally mandated emotions. In some situations individual really feel the same emotions that are required to display.

\section{Literature Review}

Emotional regulation theory provides useful framework for emotional labor. Emotional regulation theory can be defined as "the processes by which individuals influence which emotions they have, when they have them, and how they experience and express these emotions"(Gross, 1998, p. 275). As the emotions include physiological arousal and cognitions, so by regulation of physiological arousal and cognitions, one can control or manage his or her emotions to meet the organizationally mandated displayed emotions (Goffman, 1959). In the same way emotions can be regulate at workplace and when an individual experience arousal continually for a long time, it may result health problems i.e., stress. So the effects of emotional labor could be understood through this mechanism (Grandey, 2000).

Various researches have been conducted to investigate the factors that can mitigate the harmful effects of emotional labor on employee's mental health and their work productivity, such as support, that can be either social support(Abraham et al., 1998)or perceived organizational support (Duke, Goodman, Treadway, \& Breland, 2009).

Perceived organizational support (POS) can be defined as the employee's beliefs regarding the level to which an organization values their contributions and cares about their well-beings and satisfies socioemotional requirements (Eisenberger, Huntington, Hutchison, \& Sowa, 1986). According to the Rhoades and Eisenberger (2002) perceived organizational support should be increase through three kind of perceived positive treatments received from the institute. The first one is fairness. It refers to the procedural justice that is concerned to the fairness regarding the conducts that is used in the delivery of resources (Greenberg, 1990). The indication of employee's welfare through the repeated occurrence of fairness in resolutions regarding the resource distribution must have robust increase effect on perceived organizational support. The second one that should increase perceived organizational support is supervisory support. Employees generally develop their perception about their evaluation by their respective organizations; they generate opinions regarding their supervisory support for their assistances and concerns about their well-being. As, supervisors are viewed as an organizational agent that is involved in the employee's performance evaluation and distribution of the resources, therefore employees evaluate their supervisor's actions as an organization's actions for their employees. Lastly, the third one is rewards and workplace environment. The number of studies has been conducted to examine the effects of rewards and workplace environment such as up gradation, pay and role conflicts. Perceived organizational support, according to Shore and Shore (1995), should be positively linked to the resource practices, because it viewed as a respect for employee's aids to their organization.

\section{Rationale}

One of the significant theories that can explain the behavior in organization is Social exchange theory (SET) (Cropanzano \& Mitchel, 2005). According to social exchange theory employees reciprocate to the beneficial actions which may include pay, access to the information and work conditions that can aid to job performance, respect or support (Blau, 1964).This perceived organizational support can lead the employee to reciprocate the organizational support through the devotion to the emotions that are organizationally expected (display rules) which may result in decrease of emotional labor (Nixon, Yang, Spector, and Zhang, 2011). So that it is hypothisized that: "The percieved organizational support will be the significant predictor of emotional labor"

A severe increase in emotional labor in the new job market experienced by many nurses results increase in job stress, poor health condition, greater self-alienation and sudden depressive moods (Kovacs, Kovacs, \& Hegedus, 2010). The connection between nurses and emotional labor has been explored by only a few studies in spite of prominent psychological change of nurse's health (Yoon \& Kim, 2013). The worker's job related stress level may be influenced by the unintentional expression of emotion and low satisfaction level of job in the workplace. 
It is very important that more researches, which contemplate the emotional labor importance and unfavorable mental health effects, be carried out (Kim, Chang, Kim, \& Roh, 2002).

\section{Method}

\subsection{Selection Criteria}

The present study was a correlational study, aimed to explore the effect of perceived organizational support on emotional labor among nurses. Emotional labor scale and scale for perceived organizational support was used. Sample was comprise of 200 nurses both Males $(\mathrm{N}=100)$ and Females $(\mathrm{N}=100)$ from different hospitals and clinics with age range 20-51 $(M=30.50 ; S . D=4.40)$. Participants were assessed by the survey of perceived organizational support (SPOS) and Dutch questionnaire on emotional labor (D-QEL).

\subsection{Procedure}

Data was collected through convenient sampling technique from the different hospitals and clinics. Participants were instructed properly and made sure about the confidentiality of the information which they were provided. Consent form was also presented to participants, which was attached with the questionnaires. Questionnaire of perceived organizational support and emotional labor were provided to them with the instructions that the data will be used only for research purpose and there is no right and wrong response, so response all the item as honestly as you can. At the end of the completion of the questionnaire, their participation ware appreciated.

\subsection{Statistical Analysis}

Different statistical analyses were used to analyze the data. Cronbach's alpha coefficient reliability was used to find the internal consistency of the scales. Descriptive statistic was used to find the mean, standard deviation, score ranges, skewness and kurtosis of the data on perceived organizational support and emotional labor. In order to investigate the effect of perceived organizational support on emotional labor among nurses, regression analysis was used.

\section{Results}

The purpose of the current study is to investigate the effect of the perceived organizational support on emotional labor among nurses. Different analyses were computed to test the different hypothesis. Which include Descriptive statistics, Cronbach's alpha coefficient reliability, and regression analysis. The tabulated results was as follow

Reliability estimates and descriptive statistics of scales and sub-scales.

Cronbach's alpha coefficient for scales and its subscales were computed to explore the internal consistency and the descriptive statistics of the study variables.

Table 1. Cronbach's alpha and Descriptive Statistics for Study Variables $(\mathrm{N}=200)$.

\begin{tabular}{ccccccccc}
\hline \multirow{2}{*}{ Measures } & \multirow{2}{*}{$\begin{array}{c}\text { No.of } \\
\text { items }\end{array}$} & $\alpha$ & \multirow{2}{*}{$*$} & \multirow{2}{*}{$S D$} & \multicolumn{2}{c}{ Range } & \multirow{2}{*}{ Skewness Kurtosis } \\
\cline { 6 - 7 } & & & & \multicolumn{2}{c}{ Potential Actual } & & \\
\hline EL & 13 & .79 & 28.13 & 5.57 & $13-52$ & $13-51$ & 1.08 & 2.48 \\
SA & 5 & .70 & 8.40 & 2.70 & $5-20$ & $5-20$ & 1.53 & 4.52 \\
DA & 3 & .76 & 6.95 & 2.07 & $3-12$ & $3-12$ & .14 & -.28 \\
EC & 2 & .74 & 5.11 & 1.41 & $2-8$ & $2-8$ & .38 & -.25 \\
SU & 3 & .78 & 17.16 & 2.81 & $3-12$ & $9-24$ & -.06 & -.26 \\
SPOS & 8 & .89 & 21.80 & 6.58 & $8-40$ & $9-40$ & 1.40 & 1.00 \\
\hline
\end{tabular}

Note. $\mathrm{EL}=$ emotional labor; $\mathrm{SA}=$ surface acting; $\mathrm{DA}=$ deep acting; $\mathrm{EC}=$ emotional labor; $\mathrm{SU}=$ support; $\mathrm{SPOS}=$ survey of perceived organizational support.

Table 1 show the item no, alpha reliabilities, mean, standard deviation, score ranges, skewness and kurtosis of the emotional labor scale and its sub scales and survey of perceived organizational support. The reliability of emotional labor scale and its sub scale ranges from .70 to .79 which shows that the internal consistency of scale and its subscale is good. The reliability of the survey of perceived organizational support is .89 which suggests that the internal consistency of the scale is very good. The mean value indicate the average scores on each scale and its subscales. Standard deviation refers to the difference between the scores and mean of each variable. 
Skewness indicates the presence of higher values or lower values in the distribution. The skewness values of the scales and their subscales lies within the desired range of the skewness that is +1.5 to -1.5 , which indicate that the distribution lies within. Negative values indicate the occurrence of lower values and tail toward the left side whereas positive values indicate the occurrence of high values and tail toward the right side. Kurtosis indicates the sharpness of the peak of the distribution. Values of kurtosis shows that the sample' scores are normally distributed.

\section{Effect of perceived organizational support on emotional labor}

Simple linear regression was computed to explore the role of perceived organizational support in the prediction of emotional labor among nurses. The results are as follow

Table 2. Simple Linear Regression Analysis Showing the Effect of Perceived Organizational Support in the Prediction of Emotional Labor $(\mathrm{N}=200)$.

\begin{tabular}{ccccccc}
\hline Variables & $B$ & $S . E$ & $\beta$ & $R^{2}$ & $F$ & $P$ \\
\hline Constant & 31.57 & 1.34 & & & & \\
POS & -0.15 & 0.05 & $-0.18^{* *}$ & 0.03 & $7.11^{* *}$ & 0.08 \\
\hline
\end{tabular}

Note. $\mathrm{POS}=$ perceived organizational support. $* P \leq .05, * * P \leq .01,{ }^{*} * * P \leq .001$.

Table 2 shows that $3 \%$ of variance can be accounted by the perceived organizational support on emotional labor. The value of $R$ square explains the variance caused by independent variable.

\section{Discussion}

Nursing is one of the highly important, respected as well as tough and stressful occupations because they offer care services for patients which cause an increased level of job related stress (Lin, Probst, \& Hsu, 2010) which affects nurses' mental as well as physiological health. A profound knowledge of organizational support and emotional labor should be acquired and the ways to prevent negative affect of emotional labor on mental health should be find out.

This study offers the understanding to the relationship between perceived organizational support and emotional labor among nurses. Dutch questionnaire of emotional labor and short version of survey of perceived organizational support were used to analyze the relationship between the study variables. Different statistical analyses such as Cronbach's alpha coefficient reliability, descriptive statistics and regression analysis were used.

In the present study, the effect of perceived organizational support on emotional labor was explored. It was hypothesized that 'the perceived organizational support will be significant predictor of emotional labor'. The results of the present study support this hypothesis and revealed that perceived organizational support significantly predict emotional labor. One of the reasons of this strong effect of perceived organizational support on emotional labor is norm of reciprocity. The perception of organizational support encourages the employees to involve more in the organization and to put extra effort in their jobs (Saks, 2006). Moreover, they become more dedicated to their organizations (Vandenberghe, Bentein, Michon, Chebat, \& Tremblay, 2007).

According to social exchange theory employees reciprocate to the beneficial actions which may include pay, access to the information and work conditions that can aid to job performance, respect or support (Blau, 1964).Moreover, with reference to norm of reciprocity, the beneficiary of such aids is morally indebted to repay the contributor (Gouldner, 1960). When the needs of employees are fulfilled with the expected authenticity, it has been found that employees reciprocate to the perceived organizational support through the shift in attention and extra efforts towards the achievement of organization's goals (Eisenberg, Fasolo, \& Davis-LaMastro, 1990) which results decrease in emotional labor (Nixon, Yang, Spector, \& Zhang, 2011).

\section{Implications}

This study contribute to the literature of emotional labor among nurses and offers a more direct understanding regarding the relationship between perceived organizational support and emotional labor. The findings of this study benefits the human and organization resource managements in health care organizations. The understanding of these variables can help the administrators of the health care organizations to facilitate the mental health of the nurses by improving the stressful work conditions and organizational support.

\section{Limitations and Recommendations}

Although this study has a valuable implications for the health care as well as other organizations. Some of the limitations have been acknowledged that can be address by future researches in this field. First, the sample and 
its homogeneity possibly restrict its strength to discover the associations that characterized a broader segment of the population of the nurses, therefore, it is suggested for the future research that the sample size should be bigger and from different regions, so that it will increase the generalizability of the findings. Secondly, the study was a correlational study which does not provide the cause and effect relationship. It is suggested that the experimental studies should be conducted to explore the cause and effect relationship between perceived organizational support and emotional labor.

\section{Conclusion}

The purpose of the present study was to develop a health-care model of emotional labor which could help the organizations to understand the role of perceived organizational support on the reactions to the strain of the emotional labor. The present study revealed that perceived organizational support is a significant predictor of emotional labor. If nursing administrators understand that nurses may suffer from negative health conditions, and organizational support can facilitate their mental health, Informal types of organizational support (e.g., a perception that the organization is concerned with one's personal life) are important for expatriate success, and should be incorporated into expatriate programs. Psychotherapy and counseling services can be helpful to reduce their psychological problems that could be caused by the negative effect of emotional labor and will improve their productivity.

\section{References}

Abraham, E., Anzueto, A., Gutierrez, G., Tessler, S., San Pedro, G., Wunderink, R., \& Cooney, R. (1998). Double-blind randomised controlled trial of monoclonal antibody to human tumour necrosis factor in treatment of septic shock. The Lancet, 351(9107), 929-933. Retrieved from https://www.ncbi.nlm.nih.gov/pubmed/9734938

Ashforth, B. E., \& Humphrey, R. H. (1993). Emotional labor in service roles: The influence of identity. Academy of Management Review, 18(1), 88-115. Retrieved from https://www.jstor.org/stable/258824

Blau, P. M. (1964). Exchange and power in social life. Transaction Publishers.

Brotheridge, C. (2006). A review of emotional labour and its nomological network: practical and research implications. Ergonomia, 28(4), 295-309.

Brotheridge, C. M., \& Grandey, A. A. (2002). Emotional labor and burnout: Comparing two perspectives of "people work". Journal of Vocational Behavior, 60(1), 17-39. https://doi.org/10.1006/jvbe.2001.1815,

Cropanzano, R., \& Mitchell, M. S. (2005). Social exchange theory: An interdisciplinary review. Journal of Management, 31(6), 874-900. https://doi.org/10.1177/0149206305279602

Duke, A. B., Goodman, J. M., Treadway, D. C., \& Breland, J. W. (2009). Perceived organizational support as a moderator of emotional labor/outcomes relationships. Journal of Applied Social Psychology, 39(5), 1013-1034. https://doi.org/10.1111/j.1559-1816.2009.00470.x

Eisenberg, R., Fasolo, P., \& Davis-LaMastro, V. (1990). Perceived organizational support and employee diligence, commitment, and innovation. Journal of Applied Psychology, 75(1), 51-59. https://doi.org/10.1.1.529.8528\&rep=rep1\&type

Eisenberger, R., Huntington, R., Hutchison, S., \& Sowa, D. (1986). Perceived organizational support. Journal of Applied Psychology, 71(3), 500-507. Retrieved from http://classweb.uh.edu/eisenberger/wp-content/uploads/sites/21/2015/04/22_Perceived_Organizational_Sup port.pdf

Fisher, C. D., \& Ashkanasy, N. M. (2000). The emerging role of emotions in work life: An introduction. Journal $\begin{array}{lll}\text { of } & \text { Organizational }\end{array}$ https://doi.org/10.1002/(SICI)1099-1379(200003)21:23.0.CO;2-8

Goffman, E. (1959). The moral career of the mental patient. Psychiatry, 22(2), 123-142. DOI:10.1080/00332747.1959.11023166

Gouldner, A. W. (1960). The norm of reciprocity: A preliminary statement. American Sociological Review, 25(2), 161-178.

Grandey, A. A. (2000). Emotional regulation in the workplace: A new way to conceptualize emotional labor. Journal of Occupational Health Psychology, 5(1), 95-110. https://doi.org/10.1037//1076-8998.5.1.95

Greenberg, J. (1990). Organizational justice: Yesterday, today, and tomorrow. Journal of Management, 16(2), 399-432. https://doi.org/10.1177/014920639001600208 
Gross, J. J. (1998). The emerging field of emotion regulation: An integrative review. Review of General $\begin{array}{llll}\text { Psychology, 2(3), } & \text { 271-299. } & \text { Retrieved }\end{array}$ http://citeseerx.ist.psu.edu/viewdoc/download?doi=10.1.1.585.6555\&rep=rep1\&type=pdf

Hochschild, A., Irwin, N., \& Ptashne, M. (1983). Repressor structure and the mechanism of positive control. Cell, 32(2), 319-325. https://doi.org/10.1016/0092-8674(83)90451-8

Kim, S. Y., Chang, S. J., Kim, H. R., \& Roh, J. H. (2002). A study on the relationship between emotional labor and depressive symptoms among Korean industrial service employees. Korean Journal of Occupational and Environmental Medicine, 14(3), 227-235. https://doi.org/10.1186/s40557-018-0229-9

Kovács, M., Kovács, E., \& Hegedüs, K. (2010). Emotion work and burnout: Cross-sectional study of nurses and physicians in Hungary. Croatian Medical Journal, 51(5), 432-442. https://doi.org/10.3325/cmj.2010.51.432

Leary, M. R. (1995). Self-presentation: Impression management and interpersonal behavior. Brown \& Benchmark Publishers.

Lin, H. S., Probst, J. C., \& Hsu, Y. C. (2010). Depression among female psychiatric nurses in southern Taiwan: main and moderating effects of job stress, coping behaviour and social support. Journal of Clinical Nursing, 19(15-16), 2342-2354. https://doi.org/10.1111/j.1365-2702.2010.03216.x

Morris, J. A., \& Feldman, D. C. (1996). The dimensions, antecedents, and consequences of emotional labor. Academy of Management Review, 21(4), 986-1010. https://doi.org/10.5465/amr.1996.9704071861

Nixon, A. E., Yang, L. Q., Spector, P. E., \& Zhang, X. (2011). Emotional labor in China: do perceived organizational support and gender moderate the process? Stress and Health, 27(4), 289-305. https://doi.org/10.1002/smi.1359

Rhoades, L., \& Eisenberger, R. (2002). Perceived organizational support: a review of the literature. Journal of Applied Psychology, 87(4), 698-714. https://doi.org/10.1037//0021-9010.87.4.698

Saks, A. M. (2006). Antecedents and consequences of employee engagement. Journal of Managerial Psychology, 21(7), 600-619. https://doi.org/10.1108/02683940610690169

Shore, L. M., \& Shore, T. H. (1995). Perceived organizational support and organizational justice. Organizational politics, justice, and support: Managing the social climate of the workplace, 149-164.

Vandenberghe, C., Bentein, K., Michon, R., Chebat, J.-C., \& Tremblay, M. (2007). An examination of the role of perceived support and employee commitment in employee-customer encounters. Journal of Applied Psychology, 92(4),1177-1187. https://doi.org/10.1037/0021-9010.92.4.1177

Yoon, S. L., \& Kim, J. H. (2013). Job-Related Stress, Emotional Labor, and Depressive Symptoms Among Korean Nurses. Journal of Nursing Scholarship, 45(2), 169-176. https://doi.org/10.1111/jnu.12018

\section{Copyrights}

Copyright for this article is retained by the author(s), with first publication rights granted to the journal.

This is an open-access article distributed under the terms and conditions of the Creative Commons Attribution license (http://creativecommons.org/licenses/by/4.0/). 